\title{
Factors Influencing Strategic Options Of Managed Service Adoption By Telecommunication Operators: The Case Of Sri Lanka
}

Hassan Ismail, Asian Institute of Technology, Thailand

Nazrul Islam, Asian Institute of Technology, Thailand

\begin{abstract}
The market pressure on the mobile operators to improve bottom line, network performance, competence needs and rapid changing business environment led the operators to adopt managed services at different levels in their operation. Transferring value chain activities to an expert service provider is called a "managed service".

Managed services are a spectrum of solutions offering incremental levels. Existing practices indicate five levels of managed services in the spectrum viz transaction, task, project, service management, service and capacity management based.

The purpose of this research is to identify the factors influencing managed services at different levels in the context of a developing country. For this intent, this research adopted a case study approach of the Sri Lankan telecom industry covering all mobile operators of the country.

The findings of this study show a clear pattern between levels from Level-1 to Level-5. Level 1 is almost as subset of level 2, and level 4 is a subset of level 5. Five levels of managed services can be divided into three distinct groups, levels $1 \& 2$, level 3 and levels $4 \& 5$. Organizational and industry dynamics factors influence all levels. However, national regulatory environment factors are very important in adopting managed services at levels $4 \& 5$. The existing studies look the factors influencing managed services in general. This study is unique as it identifies the factors influencing managed services at each level and prioritized them. This will help operators to select a level of adoption instead of adopting managed services on a trial and error basis.
\end{abstract}

Keywords: Managed Services; Organizational; Industry Dynamics; Regulatory Environment

\section{INTRODUCTION}

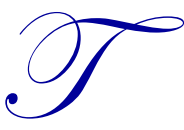

raditionally telecom operators' value chain activities were handled in-house, but today some of the value chain activities apart from marketing and sales are transferred to third party expert service providers (Domberger, 1998). Transferring value chain activities to an expert service provider is called a "managed service" in the telecom industry. Various terminology is used in other industries, for example in IT this is called outsourcing. This phenomenon is driven by the rapid changes in technology cycles, the changes in government policies regarding liberalizing the telecom industry from a monopoly to competition and most importantly, the increase in demand from the customers resulting in a more competitive industry. In the US, hosting services contracts are well received, whilst other types of managed services contracts have been more prevalent in Europe and Asia (Corbett, 2005). 
Analysis of the current trends in the telecommunication industry and their potential development advocates continued growth and popularity of the managed services market (Ericsson, 2007). Some of the forces and circumstances advocating the continued growth of the managed services market over the next few years are:

- The operator's competitive edge continuing to shift to innovations in product packaging from network and service management (Quinn \& Hilmer, 1994).

- The operator focusing resources on revenue generation instead of network management as a result of the shift in responsibility of roles in the value chain.

- In a time of increasing communication network complexity, individual telecom operators must be extremely competent to meet both the challenge of transitioning between technologies and the operational challenges of managing and optimizing the potential of co-existing technologies. Hence, network management will continue to increase demands on operator capabilities and proficiency. This in turn will mean that operators might not have an intensive to develop the required expertise internally while there are third party providers who have the required competencies to manage these networks.

- The operator environment is becoming more IT- oriented with the increase of end-user services and applications. Multiple operators in a geographic region can be supported by a managed services provider. Managed services providers can deliver the required competencies for both, transitioning between technologies and managing existing technologies, and are accustomed to operating at the rapid pace demanded by the competitive telecoms market.

The degree of managed services adopted by each operator varies depending on their organizational readiness and operational complexity. Managed services are a spectrum of solutions offering incremental levels. At the lower end of this spectrum, at level 1, it is a transaction based arrangement related to specific skilled resources provided by a vendor to supplement the local workforce for the basic operations and maintenance of a company's technology assets. This ensures that when problems occur, the relevant resources, competency, reserve equipment and parts are provided when they are required. Here the activities performed by the vendor are instructed by the client and the vendor doesn't take any risk or accountability. For example, getting an expert resource from a vendor to manage trouble shooting in a proprietary core network platform or to man the network operations center during sudden peaks.

Level 2 is a task based arrangement where the vendor only performs certain tasks or part of the network elements and are responsible for their activities, for example, field maintenance. At level 3, the arrangement is project based where the vendor takes responsibility for the network rollout project deliverables and is responsible for the execution of the project end to end. The client duty is restricted to monitoring and control. Project deliverables should be delivered by the vendor as per the mutually agreed service level agreements (SLA). For example, the construction of telecommunication base stations. At level 4 the services provider takes complete ownership and responsibility for the delivery (Manish \& Rohini, 2007) of both technical and business services according to mutually agreed key performance indicators (KPIs). In other words, level 4 is service management based. For example, operations and maintenance of telecommunication networks (2G-second generation wireless telephone technology, 3G-third generation wireless telephone technology, 4G-fourth generation wireless through long term evolution with frequency division duplexing etc.) by managed service provider with mutually agreed key performance indicators.

At the top of the spectrum, level 5, the service provider takes up complete end-to-end (E2E) accountability for the communications infrastructure design, implementation, deployment, management and provides the required capacity as and when required. Of course, all of it is developed in collaboration with the operator to meet their unique and current business strategy. The operator is able to focus its skills and assets externally on its markets and customers because the provider typically takes up the demands of management that come with functioning a company's internal communications operations. Thus, level 5 is service and capacity management based where the managed service provider is responsible for designing, building, operating and maintaining telecommunication networks (2G,3G,4G etc.) with mutually agreed key performance indicators (KPIs).

The dilemma of operators is to choose on the suitable level of adoption of managed services within the managed services continuum. To adopt the right level of managed services within the organization one needs to understand the organizational readiness, managed services maturity level and strategic intent prior to the adoption of managed services. While the management of telecom operators look at it from a strategic initiative to take the business to the 
next level, others, especially staff and other stakeholders consider it a threat that could render them jobless and threaten their opportunity for development in the telecom field. The operators in their endeavor to adopt managed services face several problems both internally and externally.

Some of the internal problems are as follows:

- The human factors, corporate culture and particularly, the influence of trade unions are some of the critical challenges in adopting a higher degree of managed services where staff must be moved from the operator organization to the managed service provider organization.

- Non-availability of adequately specialized vendors with good credentials to provide the services

- Transfer/migration costs, particularly, when there is a mirroring of human resources and systems between the operator and managed service provider.

- Costs incurred in network transformation, for example, network consolidation including re-design of network, re-deployment equipment etc.

- Redundancy costs, incurred due to challenges in navigating human resources and reduced performance when the workforce transfer is not smooth.

Some of the external problems are as follows:

- Policies and issues related to hosting the country's subscriber data outside the country

- Inadequate legal provisions to deal with cyber security and data related violations

- Government fiscal policies on duty concessions granted by the board of investment to the telecom industry and taxation related to the services obtained by the telecom operators from vendors must be aligned to avoid double taxation.

- Being wary of the threat of cartelization of managed service providers.

Knowledge of the major factors influencing managed services at different levels and their degree of importance will help operators decide the degree of managed services that should be adopted and what the key drivers are with respect to the level of adoption of managed services. It will also help national policy makers create a necessary regulatory policy framework for the managed services' ecosystem. Furthermore, this information will facilitate both the service provider and the service seeker to design the necessary operational framework for adopting the right level of managed services within the regulatory environment.

Managed services are a fairly new approach in the telecom industry with relatively few published articles on the topic. However, there are some white papers published by some leading service provider organizations such as Ericson, Alcatel-Lucent, Nokia Siemens, Motorola, some consulting organizations and the Institute of Outsourcing. There are number of research journal articles on service outsourcing in the IT industry. These existing studies identified the factors influencing IT outsourcing and managed services in general and not for any specific level in the adoption spectrum discussed above. Therefore, a study to identify the factors influencing managed services at a specific level of adoption of managed services will be useful for operators to select a level of adoption based on their organization readiness and strategic intent instead of adopting managed services on a trial and error basis. Further it would be interesting to see if the factors vary depending on the context. Thus, a study within the context of developing countries would contribute to the literature.

Therefore, the aim of this research is to identify the factors influencing managed services at different levels in the context of a developing country, and to investigate if there exists any pattern in the sets of factors among different levels of managed services. For this purpose, this research adopted a case study approach of the Sri Lankan Mobile telecom industry covering all mobile operators of the country. The Sri Lankan mobile telecom market more or less reflects the markets of the South and South East Asian region in a wider context.

The following section presents the status of managed services in the Sri Lankan telecom industry, and is followed by study framework, findings and discussion, management implications and the conclusion. 


\section{THE SRI LANKA MOBILE TELECOM INDUSTRY AND ITS ADOPTION OF MANAGED SERVICES}

The first cellular phone operation in Sri Lanka started in 1989. Prior to 1989 there was only a one wire line operator; fixed access and one hundred percent government owned. Today, in addition to the fixed line operated by the government, there are five mobile operators engaged in voice \& data telephony.

The profiles of the five mobile operators are presented in Table 1 . Due to confidentiality purposes the names of the companies are not disclosed. The five companies are referred to as Operators A, B, C, D \& E. Of the five mobile telecommunication operators, operator $\mathrm{C}$ is a state controlled company and operator $\mathrm{D}$ is a public quoted company with a combined market share of 70 percent (Company annual reports $C \& D, 2016)$. Operator $D$ is the largest company having 45 percent market share (Company D annual report, 2016) market share. The other three operators are private companies. Operators $\mathrm{C} \& \mathrm{D}$ have acquired $2 \mathrm{G}, 3 \mathrm{G} \& 4 \mathrm{G}$ technologies whereas operators A, B \& E have only $2 \mathrm{G} \&$ $3 \mathrm{G}$ technologies.

Table 1. Profiles of the five Mobile Operators

\begin{tabular}{c|l|c|c|c|c|c|c|}
\hline $\begin{array}{c}\text { Mobile } \\
\text { Operators }\end{array}$ & $\begin{array}{c}\text { Ownership } \\
\text { Type }\end{array}$ & $\begin{array}{c}\text { Launched } \\
\text { services }\end{array}$ & $\begin{array}{c}\text { Technologies } \\
\text { Used }\end{array}$ & $\begin{array}{c}\text { Customer } \\
\text { Base }\end{array}$ & $\begin{array}{c}\text { Annual Company } \\
\text { Revenue/M USD }\end{array}$ & \multicolumn{2}{c|}{ No of employees } \\
\hline A & Private Owned & 1989 & $2 \mathrm{G} / 3 \mathrm{G}$ & $3,700,000$ & 133.20 & 172 & 780 \\
\hline B & Private Owned & 1993 & $2 \mathrm{G} / 3 \mathrm{G}$ & $1,100,000$ & 39.60 & 60 & 155 \\
\hline C & State Controlled & 1993 & $2 \mathrm{G} / 3 \mathrm{G} / 4 \mathrm{G}$ & $6,600,000$ & 260.48 & 325 & 1036 \\
\hline D & Public Quoted & 1995 & $2 \mathrm{G} / 3 \mathrm{G} / 3.5 \mathrm{G} / 4 \mathrm{G}$ & $11,000,000$ & 503.20 & 712 & 2372 \\
\hline E & Private Owned & 2009 & $2 \mathrm{G} / 3 \mathrm{G}$ & $2,100,000$ & 75.60 & 25 & 200 \\
\hline
\end{tabular}

\section{MOBILE MARKET}

The mobile market in Sri Lanka is relatively small, with a total of 24.5 million mobile subscribers, and is highly competitive. The government of Sri Lanka has pegged a floor price on mobile tariff; one of the few countries in which this is the case. The market leader (Operator D) has almost already matched this price and as a result, competitors cannot lower their tariffs much further. Therefore, the other players cannot compete with the market leader on cost basis. The limited possibility of further price competition has encouraged operators to focus competition on service (e.g. loyalty programs) and product innovation.

Mobile Penetration has grown steadily over the last ten years. However, the rate of penetration growth has slowed down since 2015 as the market is becoming increasingly saturated. In the year 2006, the number of SIMs per population was around 27 percent and in the year 2015 it was around 130 percent with an annual average growth rate of 10 percent. (ITU, 2016)

In recent years Operators $\mathrm{C}$ and $\mathrm{D}$ have made considerable $3 \mathrm{G}$ investment. Operator $\mathrm{D}$ now has a $3 \mathrm{G}$ population coverage of 84 percent and Operator C, 80 percent. Mobile broadband penetration in Sri Lanka is currently at 25 percent (GSMA, Q3 2016) and smart phone penetration is at 35 percent (2016 press release). 4G was introduced to the country in 2013, while $3 \mathrm{G}$ has been in operation since 2008. Only two operators (C\&D) are offering 4G Services.

All operators have seen significant revenue growth during the last ten years driven by increasing subscriber growth and the late uptake of $3 \mathrm{G}$ services/data. In recent years, the slow-down in the growth rate of penetration combined with stable average revenue per user (ARPUs) have resulted in a dramatic decline in the rate of revenue growth although the revenue growth remains robust compared to many other advanced mobile markets (Lurin \& Legrand, White paper, 2014). Margins for the largest two operators in Sri Lanka have been remarkably consistent over the last five years (Company Annual Reports, C\&D, 2011-16). The average profit margins for the two largest operators is 31 percent (Company Annual Reports C\&D, 2011-16). 


\section{Adoption Level of Managed Services in Sri Lanka}

In Sri Lanka, managed services and the desire to adopt managed services is gaining momentum and is gradually becoming the preferred strategy adopted by major mobile telecom operators in the country. All five mobile operators in the country have adopted different levels of managed services. Out of the five mobile operators, operator E has adopted the highest level (Level 5) of managed services, operator D has adopted level 4 of the managed services spectrum (limited engagement) and operator A intends to adopt the fourth level of managed services as per the case study. Operators B \& C are adopting the $3^{\text {rd }}$ level of managed services but there is no sign of either operator moving into the next phases of managed services because operator $\mathrm{B}$ is exploring the possibility of selling their operations in the near future and operator $\mathrm{C}$ is a state controlled company with a strong trade union.

\section{Regulatory Environment}

Since the liberalization of the telecom markets in Sri Lanka in 1988, there have been a number of significant regulatory policies formulated and implemented in the areas of allocation of frequency spectrum, operator licensing, tariff approvals, liberalization of an external gate way for international call termination etc. Government policies and regulations related to issuing licenses and allocation of frequency spectrum etc. have moved from conservative to liberal over the years (Samarajeewa \& Dokeniya, 2004 and Knight-John, 2011).

However, there aren't any regulatory policy frameworks specifically targeting managed services and active and passive sharing. Although, there are no restrictions from the regulator for adopting managed services in Sri Lanka, there are many challenges requires the attention of the policy makers as highlighted in the introduction to facilitate the effective adoption of managed services in Sri Lanka. The specialized international vendors operating in Sri Lanka - Ericsson, Huawei, Alcatel Lucent, Cisco, ZTE etc. - can provide managed services.

\section{THE STUDY FRAMEWORK}

\section{Conceptual Framework}

Figure 1 shows the conceptual framework of the study. The left column shows the factors affecting the managed services in the telecom industry. The column on the right shows the different levels of the managed services; transaction based, task based, project based, services management based and services \& capacity management based. 
Figure 1. Conceptual Framework of the study

\begin{tabular}{|l|}
\hline \multicolumn{1}{|c|}{ 1. Organizational } \\
\hline \\
- \\
Clear commercial incentives and \\
disincentives \\
- Compatibility of Service Level \\
Agreements (SLAs) \\
- Cost leadership \\
\end{tabular}

2. National Regulatory Environment

- Regulatory environment

- Active infrastructure sharing policies

- Passive infrastructure sharing policies

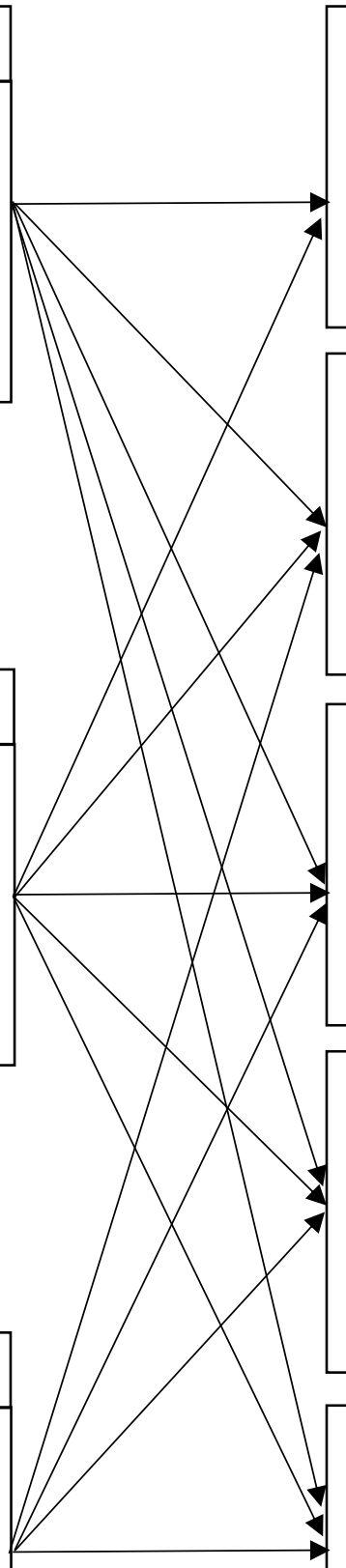

Level 5 Service and Capacity Management Based

The service provider takes complete ownership for the delivery of the capacity, coverage and services with end to end (E2E) key performance indicators (KPIs) (Both technical and business KPIs).

\section{Level 4 Service Management Based}

The service provider takes complete ownership for the delivery of services with end to end (E2E) key performance indicators (KPIs) (both technical and business KPIs).

\section{Level 3 Project Based}

Vendor responsibility for a project and are responsible for the day to day running of a particular project. The client duty is restricted to monitoring and control. Project deliverables are met by vendor as per the mutually agreed SLA.

\section{Level 2 Task Based}

The vendor only performs certain tasks or part of the network elements and are responsible for their activities.

\section{Industry Dynamics}

- Regulatory environment

- Active infrastructure sharing policies

- Passive infrastructure sharing policies

\section{Level 1 Transaction Based}

Specific skilled resources to supplement local workforce is provided by vendor (here the activities performed by vendor are as instructed by client and the vendor do not take on any risk or accountability). 


\section{Factors Affecting Managed Services}

The factors were grouped into three major categories namely organizational (Moller \& Halinen, 1999; Barney, 1991) industry dynamics (Barney, 1991) and regulatory environment (Knight-John, 2011).

Managed services' decision making in the telecom industry is a triad between abilities, motivation and opportunities (Moller \& Halinen, 1999). Understanding organizational factors is important to determine abilities and motivations. Companies are a collection of tangible and intangible assets including capabilities (Barney, 1991). Adopting a particular level of managed service is influenced by reasons related to the operator's tangible and intangible assets and capabilities. These include financial, non-financial, risk mitigation, human resources and trade unions etc.

It is the industry dynamic factors that stand for opportunities \& threats, and industries vary considerably in terms of chances that they are presented for growth (Barney, 1991). The diverse characteristics of business, competition, cost and market factors between industries create variations in terms of the pressures they put on companies to operate at an optimal cost structure.

Targeted government policies have the power to bridge the resource gaps of the telecom industry and enhance the willingness of decision makers to engage in managed services. According to the regulatory and legal framework of a country is an essential requirement for the successful implementation of managed services in the telecom industry (Knight-John, 2011). There are a number of examples for the variety of market failures stemming from a high level of government involvement, insufficient legal framework, delay in deregulation in government policies, controlling mergers \& acquisition and underdeveloped markets.

Factors affecting managed services found in the literature are shown in Annexure 1. Only representative factors are shown for each category in the figure above. A comprehensive list of factors for each category influencing managed services was identified upon the completion of the case studies on the telecom operators in Sri Lanka.

\section{Levels of Managed Services}

Discussions of the five levels of the managed services i.e. transaction based, task based, project based, service management based, service \& capacity management based have been presented in introduction of this paper.

\section{Research Design}

This research is an exploratory case study which investigates major organizational, industry and regulatory environmental factors that influence managed services decisions in the telecom industry in Sri Lanka and their significance at different levels of managed services.

All five mobile operators in Sri Lanka were selected for this study. One of the authors himself has professional contacts with all five mobile operators as he has worked in some of these companies and is still working at one of the companies in the senior leadership team. This conceded the researcher to get in-depth and detailed information during the research period. Due to confidentiality purposes, the names of the companies and the participants are not disclosed. As mentioned the five companies are referred to as operators A, B, C, D \& E.

Data and information were collected through semi structured interviews, informal discussions, review of documents such as project schedules, contract documents, scope documents and the researcher's observations. The data from these sources were triangulated to arrive at a general understanding of each operator.

Publications by the firms' product brochures, annual reports, industry publications, websites and any other published data were used in studying the operators considered for this study. Information gathered through secondary resources were further supplemented by sector reports, statistical information for developing markets and a review of governing rules and regulations for the telecom industry activities to develop a more complete understanding of changes in the external environment. 
Data collection was carried out in two stages, In the first stage, semi structured interviews were carried out with senior management personnel to find out factors influencing the level(s) of managed services adoption in their organization. Open ended questions were prepared for face to face semi structured interviews among nineteen senior decision makers from all five mobile operators as they understood their company operations from different perspectives and were therefore suitable for gathering more holistic data. The persons interviewed are shown in Table 2. The respondents were informed of the research prior to the interviews to ensure the interviews were focused and productive.

Table 2. Interviewed personnel from five Mobile Operator

\begin{tabular}{c|c|l}
\hline Mobile Operators & $\begin{array}{c}\text { No. of personnel } \\
\text { interviewed }\end{array}$ & \multicolumn{1}{c}{ Position of interviewee } \\
\hline A & 3 & Chief Executive Officer, Chief Operating Officer, Chief Technical Officer \\
\hline B & 3 & Chief Technical Officer, Chief Financial Officer, General Manager \\
\hline C & 3 & General Manager, Chief Financial Officer, Senior Manager \\
\hline D & 5 & $\begin{array}{l}\text { Chief Operating Officer, Group Chief Technical Officer, Group Chief } \\
\text { Information Officer, Group Chief Program officer, Group Chief Financial Officer }\end{array}$ \\
\hline E & 5 & $\begin{array}{l}\text { Country Head, Chief Technical Officer, Chief Executive Officer, } \\
\text { General Manager-Supply Chain Management, Chief Financial Officer }\end{array}$ \\
\hline
\end{tabular}

A semi-structured questionnaire was sent to the interviewees prior to the interview. The face to face interviews were carried out in line with the semi structured questionnaire and follow up probing questions. Most interviews were recorded and transcribed, except those who did not permit the recording. The recorded interviews and the researcher's notes were used for coding, checking and analyzing work. Interviews with senior management lasted approximately one and a half hours to two hours each. The data and information obtained from the case study along with the list of factors obtained in the literature review were used to generate a comprehensive list of factors affecting each level of managed services.

In the second stage, all identified factors were listed in the questionnaire under different levels of managed services and the respondents were requested to rank each factor on importance on a five-point scale (on a scale of one to five, where one being of low importance and five being of high importance).

This questionnaire was administered among sixty-two participants from all mobile operators at three management categories namely senior managers, middle managers and operational managers. Fifty-six responses were received.

The participants were contacted in person via phone and emails. A summary and objectives of the research were presented. The questionnaire requested respondents to rank the importance of the factors under different levels of managed services in their firm's decision to adopt managed services. The questionnaire was duly filled and submitted to the researcher via email.

The responses for each factor were analyzed by assigning a scoring system. For example, if a factor had fifty-six responses as follows; two respondents for importance level 1, six respondents for importance level 2, nine respondents for importance level 3, seventeen respondents for importance level 4 and twenty-two respondents for importance level 5 , then,

the total score is $=2 * 1+6 * 2+9 * 3+17 * 4+22 * 5=219$

All factors were ranked from the highest score to the lowest score

\section{FINDINGS}

Table 3 presents the main activities for each level of managed services adopted by all five mobile operators in Sri Lanka. Of the five mobile telecommunication operators, only operator E is in level 5. Operators A, B and C have adopted managed services at level 3 while operator D has adopted some elements of Level 4 and is in the process of 
incorporating more elements of the services management model. Operator $\mathrm{E}$ is the last mobile telecommunication entrant of the Sri Lankan market, commencing its operation by adopting managed services at level 5 (services \& capacity management model) in 2008. Operator D engaged a senior cross functional team to study the feasibility of entering a long-term service management engagement with a suitable managed service provider. Operators A \& B also expressed their willingness to enter a services management engagement after an in-depth study of the pros and cons of adopting services management. Operator $\mathrm{C}$, being a government owned company, has a very strong labour union and will therefore find it challenging to adopt services management in the near future. As operator B's parent company is considering selling the company, the management of operator B is of the view that entering any long-term services management contract would not be appropriate at this point of time.

Table 3. Managed services activities of the five mobile operators studied

\begin{tabular}{|c|c|c|c|}
\hline $\begin{array}{c}\text { Mobile } \\
\text { Operators }\end{array}$ & Main Activities & Level of Managed Service & $\begin{array}{l}\text { Starting } \\
\text { time }\end{array}$ \\
\hline \multirow{3}{*}{ A } & Resourcing for technical operational functions & Transaction based & 1998 \\
\hline & Core network operation and maintenance & Task based & 1989 \\
\hline & End to end (E2E) network roll out & Project Based & 2007 \\
\hline \multirow{3}{*}{$\mathrm{B}$} & Resourcing for technical operational functions & Transaction based & 1996 \\
\hline & Core network operation and maintenance & Task based & 1994 \\
\hline & End to end (E2E) network rollout & Project Based & 2007 \\
\hline \multirow{3}{*}{$\mathrm{C}$} & Resourcing for technical operational functions & Transaction based & 1996 \\
\hline & Core network operation and maintenance & Task based & 1994 \\
\hline & E2E network roll out & Project Based & 2004 \\
\hline \multirow{5}{*}{$\mathrm{D}$} & Resourcing for field operations & Transaction based & 1997 \\
\hline & Core network operation and maintenance & Task based & 1996 \\
\hline & End to end (E2E) network rollout & Project Based & 2011 \\
\hline & End to end (E2E) IT projects & Project Based & 2009 \\
\hline & $\begin{array}{l}\text { End to end (E2E) call center operations and } \\
\text { management }\end{array}$ & Service Management based & 2009 \\
\hline \multirow{7}{*}{$\mathrm{E}$} & $\begin{array}{l}\text { End to end (E2E) network operation and } \\
\text { maintenance }\end{array}$ & Service Management based & 2008 \\
\hline & Resourcing for site acquisition & Transaction based & 2008 \\
\hline & End to end (E2E) IT operation and maintenance & Service Management based & 2008 \\
\hline & End to end (E2E) network rollout & Project based & 2008 \\
\hline & $\begin{array}{l}\text { End to end (E2E) Call center operations and } \\
\text { management }\end{array}$ & Service Management based & 2008 \\
\hline & Warehousing transportation and logistics & Service Management based & 2008 \\
\hline & Managing capacity and active and passive sharing & Service and Capacity Management based & 2008 \\
\hline
\end{tabular}

\section{Factors Influencing the Adoption of Managed Services at Different Levels and Their Ranking}

\section{Factors Influencing the Adoption of Managed Services at Level 1 (Transaction Based)}

Table 4a presents the factors influencing the adoption of managed services at Level 1 and their rankings. There were twenty-two factors identified at this level under two major categories, organizational and industry dynamics. There are no regulatory environment factors at this level. Of the twenty-two factors identified, fifteen factors are organizational and seven factors are regarding industry dynamics. The top five factors identified by importance are access to key competencies on a need basis, access to diverse skills and expertise/expert support, resourcing for "sudden peaks and troughs", specialized areas of work, technological complexities \& access to global resources. 
Table 4a. Level 1: Transaction Based

Table 4. Factors Influencing Managed Services at Level $1 \& 2$

\begin{tabular}{|c|c|c|c|}
\hline & $\begin{array}{ll}\text { Factor } \\
\end{array}$ & Score & Rank \\
\hline \multirow{15}{*}{ Organizational } & Resourcing for "sudden peaks and troughs" & 210 & 3 \\
\hline & Specialized areas of work & 201 & 4 \\
\hline & Non- availability of experts within the organization & 181 & 10 \\
\hline & Cost optimization & 180 & 11 \\
\hline & Scalability & 179 & 12 \\
\hline & Operational ease & 177 & 13 \\
\hline & Cost predictability & 174 & 15 \\
\hline & Staff reduction & 167 & 16 \\
\hline & Difficulty of retaining young skilled staff & 167 & 16 \\
\hline & Fixed to variable cost & 166 & 18 \\
\hline & Training and retraining & 160 & 19 \\
\hline & No risk of loss of internal expertise & 159 & 20 \\
\hline & Cost reduction & 155 & 21 \\
\hline & Legacy technology operations and maintenance & 136 & 22 \\
\hline & To improve the competency level & 177 & 5 \\
\hline \multirow{7}{*}{ Industry dynamics } & Access to key competencies on need basis & 218 & 1 \\
\hline & Access to diverse skills and expertise expert support & 216 & 2 \\
\hline & Access to global resources & 191 & 5 \\
\hline & Non-core activities to a third party & 184 & 7 \\
\hline & Technological complexities & 191 & 5 \\
\hline & To handle increase complexity & 184 & 7 \\
\hline & Need for special skills and training & 183 & 9 \\
\hline
\end{tabular}

Table 4b. Level 2: Task Based

\begin{tabular}{|c|c|c|c|}
\hline & $\begin{array}{ll}\text { Factor } \\
\end{array}$ & Score & Rank \\
\hline \multirow{19}{*}{ Organizational } & Resourcing for "sudden peaks and troughs" & 205 & 2 \\
\hline & Specialized areas of work & 198 & 5 \\
\hline & Non- availability of experts within the organization & 181 & 11 \\
\hline & Cost optimization & 180 & 12 \\
\hline & Scalability & 167 & 17 \\
\hline & Operational ease & 189 & 8 \\
\hline & Cost predictability & 178 & 13 \\
\hline & Staff reduction & 165 & 19 \\
\hline & Difficulty of retaining young skilled staff & 152 & 23 \\
\hline & Fixed to variable cost & 168 & 16 \\
\hline & Training and retraining & 169 & 15 \\
\hline & No risk of loss of internal expertise & 157 & 22 \\
\hline & Cost reduction & 183 & 10 \\
\hline & Legacy technology operations and maintenance & 142 & 24 \\
\hline & Accountability and reliability & 186 & 9 \\
\hline & To hand over some legacy nodes to a 3rd party & 171 & 14 \\
\hline & Lean organization & 167 & 17 \\
\hline & No risk of loss of control & 162 & 20 \\
\hline & Better attitude to work & 159 & 21 \\
\hline \multirow{5}{*}{ Industry dynamics } & Access to key competencies on need basis & 203 & 4 \\
\hline & Access to diverse skills and expertise expert support & 205 & 2 \\
\hline & Access to global resources & 190 & 7 \\
\hline & Non-core activities to a third party & 193 & 6 \\
\hline & Expertise or capability of vendor & 209 & 1 \\
\hline
\end{tabular}




\section{Factors Influencing the Adoption of Managed Services at Level 2 (Task Based)}

Table $4 \mathrm{~b}$ presents the factors influencing the adoption of managed services at Level 2 and their rankings. There were twenty-four factors identified at this level under two major categories, organizational and industry dynamics. There are no regulatory environment factors influencing this level of managed services. Of the twenty-four factors identified, nineteen factors are organizational and five factors are regarding industry dynamics. The top five factors identified by importance are expertise or capability of the vendor, access to diverse skills and expertise/expert support, resourcing for "sudden peaks and troughs", access to key competencies on a need basis, and specialized areas of work

\section{Factors Influencing the Adoption of Managed Services at Level 3 (Project Based)}

Table 5 presents the factors influencing the adoption of managed services at Level 3 and their rankings. There were thirty-eight factors identified at this level under three major categories; organizational, industry dynamics and regulatory environment. Of the thirty-eight factors identified, twenty-nine factors are organizational, eight factors are regarding industry dynamics and only one factor is regarding regulatory environment. The top five factors by importance are end to end vendor accountability for projects, expertise of the vendor, speedy network rollout, accountability and reliability and faster to go to market.

Table 5. Factors Influencing Managed Services at Level 3c

\begin{tabular}{|c|c|c|c|}
\hline \multicolumn{4}{|c|}{ Level 3-Project Based } \\
\hline Factor category & Factor & Score & Rank \\
\hline \multirow{29}{*}{ Organizational } & End to end vendor accountability for projects & 238 & 1 \\
\hline & Speedy network rollout & 229 & 3 \\
\hline & Accountability and reliability & 228 & 4 \\
\hline & Passive infrastructure roll out & 223 & 5 \\
\hline & Resultant based payment model & 220 & 7 \\
\hline & Compliance of service level Agreements (SLAs) & 218 & 8 \\
\hline & Economies of scale & 218 & 8 \\
\hline & Improved of focus on core business & 213 & 11 \\
\hline & Ability to manage peaks and off peaks & 207 & 12 \\
\hline & Zero inventory carrying cost & 207 & 12 \\
\hline & Focus on core companies & 204 & 14 \\
\hline & Scalability & 204 & 14 \\
\hline & Cost reduction & 204 & 14 \\
\hline & Lean organization & 203 & 17 \\
\hline & Cost optimization & 202 & 18 \\
\hline & Cost savings & 201 & 20 \\
\hline & Zero warehouse cost & 201 & 20 \\
\hline & Collaborative model & 200 & 23 \\
\hline & Increased flexibility & 200 & 23 \\
\hline & Avoid crowdsourcing & 199 & 25 \\
\hline & Cost predictability & 199 & 25 \\
\hline & Rationalized investment on new technologies & 196 & 28 \\
\hline & Risk sharing or mitigation & 196 & 28 \\
\hline & Increase ability to adopt new technologies & 193 & 31 \\
\hline & Cost leadership & 191 & 32 \\
\hline & Stretched and delayed payment terms & 190 & 33 \\
\hline & Staff reduction & 187 & 34 \\
\hline & Spare management time & 186 & 35 \\
\hline & Free cash flow & 181 & 37 \\
\hline
\end{tabular}

(Table 5 continued on next page) 


\begin{tabular}{|c|c|c|c|}
\hline Factor category & Factor & Score & Rank \\
\hline \multirow{8}{*}{ Industry dynamics } & Expertise of vendor & 229 & 2 \\
\hline & Faster go to market & 223 & 5 \\
\hline & Specialized vendors & 216 & 10 \\
\hline & High quality network build & 202 & 18 \\
\hline & Leverage unique skill in vendor & 201 & 20 \\
\hline & Ease of being update with new technologies & 197 & 27 \\
\hline & Access to best in class organization and process & 196 & 28 \\
\hline & Risk of depending on third party vendor & 182 & 36 \\
\hline Regulatory environment & To meet coverage obligation & 170 & 38 \\
\hline
\end{tabular}

Factors Influencing the Adoption of Managed Services at Level 4 (Services Management Based)

Table 6a presents the factors influencing the adoption of managed services at Level 4 and their rankings. There were sixty-one factors identified at this level under three major categories; organizational, industry dynamics and regulatory environment. Of the sixty-one factors, twenty-nine factors are organizational, twenty-nine factors are regarding industry dynamics and three factors are regarding regulatory environment. The top five factors by importance are cost reduction, scalability, compliance of service level agreements, access to key technical experts and global practices, accountability and reliability.

Table 6. Factors Influencing Managed Services at Level 4 \& 5

Table 6a. Level 4 - Managed Services

\begin{tabular}{|c|c|c|c|}
\hline Category & 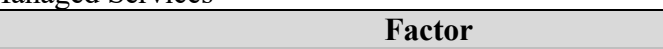 & Score & Rank \\
\hline \multirow{29}{*}{ Organizational } & Cost reduction & 430 & 1 \\
\hline & Scalability & 410 & 2 \\
\hline & Compatibility of Service Level Agreements (SLAs) & 232 & 3 \\
\hline & Accountability and Reliability & 230 & 5 \\
\hline & Focus on Key Performance Indicators (KPIs) & 228 & 6 \\
\hline & Focus on core competencies & 220 & 8 \\
\hline & Focus on end to end service quality management & 220 & 8 \\
\hline & Increase speed & 218 & 10 \\
\hline & Clear commercial incentives and disincentives & 217 & 11 \\
\hline & Improve profitability & 213 & 14 \\
\hline & Resultant based payment model & 212 & 16 \\
\hline & Economies of scale & 211 & 19 \\
\hline & Improved focus on core business & 209 & 23 \\
\hline & Fixed cost to variable cost model & 209 & 23 \\
\hline & Cost optimization & 208 & 27 \\
\hline & Cost predictability & 206 & 30 \\
\hline & Lean organization & 206 & 30 \\
\hline & Collaborative model & 205 & 33 \\
\hline & Risk sharing \& mitigation & 202 & 37 \\
\hline & Alternative method of procurement & 201 & 40 \\
\hline & Delayed and stretched out payment terms & 201 & 40 \\
\hline & Flexibility of operations & 198 & 44 \\
\hline & Management spare time & 194 & 45 \\
\hline & No risk of loss of control & 191 & 49 \\
\hline & Free cash flow & 185 & 52 \\
\hline & No risk of loss of internal expertise & 182 & 56 \\
\hline & Staff to be put to other use & 179 & 57 \\
\hline & Lower entry barriers & 178 & 58 \\
\hline & Retaining of trained staff & 164 & 60 \\
\hline
\end{tabular}

(Table 6a continued on next page) 


\begin{tabular}{|c|c|c|c|}
\hline Category & \begin{tabular}{|l|} 
Factor \\
\end{tabular} & Score & Rank \\
\hline \multirow{29}{*}{$\begin{array}{l}\text { Industry } \\
\text { dynamics }\end{array}$} & Access to key technical experts and global practices & 231 & 4 \\
\hline & Access to global resources & 226 & 7 \\
\hline & Access diverse skills and expertise & 215 & 12 \\
\hline & Leverage unique skills in vendor & 214 & 13 \\
\hline & Access to the latest technology and infrastructure & 213 & 14 \\
\hline & Improve performance of the quality of network & 212 & 16 \\
\hline & Least cost structure & 212 & 16 \\
\hline & Transform business model to compete & 211 & 19 \\
\hline & High quality network build & 210 & 21 \\
\hline & Technological complexities & 210 & 21 \\
\hline & Improve operational efficiency & 209 & 24 \\
\hline & Reliability and availability & 209 & 23 \\
\hline & Focus on the customer & 207 & 27 \\
\hline & Reduce network downtime and service degradation & 207 & 27 \\
\hline & Stiff competition & 206 & 30 \\
\hline & New services faster to market & 204 & 34 \\
\hline & Non-availability of experts within the organization & 204 & 34 \\
\hline & Process, tools and methods & 204 & 34 \\
\hline & Focus on customer acquisition & 202 & 37 \\
\hline & Increasing focus on customer & 202 & 37 \\
\hline & Ease of being updated with new technologies & 201 & 40 \\
\hline & Faster responses to complex network issues & 200 & 43 \\
\hline & Rapid change of technologies & 193 & 46 \\
\hline & Competitive advantage & 192 & 47 \\
\hline & Constant decreasing revenue and margins & 192 & 47 \\
\hline & Constant decline in the Average Revenue Per User (ARPU) & 186 & 51 \\
\hline & Technical shifts & 184 & 53 \\
\hline & Avoid investment on equipment that short end of life & 183 & 54 \\
\hline & Increase complexities & 191 & 49 \\
\hline \multirow{3}{*}{$\begin{array}{c}\text { Regulatory } \\
\text { Environment }\end{array}$} & Active sharing & 183 & 54 \\
\hline & Regulatory environment & 173 & 59 \\
\hline & Obsolete technology & 152 & 61 \\
\hline
\end{tabular}

Table 6b. Level 5 - Managed Services \& Managed Capacity

\begin{tabular}{|c|c|c|c|}
\hline Category & 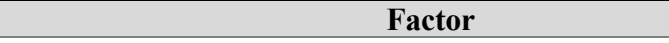 & Score & Rank \\
\hline \multirow{18}{*}{ Organizational } & Cost reduction & 229 & 5 \\
\hline & Scalability & 180 & 67 \\
\hline & Compatibility of Service Level Agreements (SLAs) & 243 & 1 \\
\hline & Accountability and Reliability & 237 & 2 \\
\hline & Focus on Key Performance Indicators (KPIs) & 220 & 16 \\
\hline & Focus on core competencies & 221 & 15 \\
\hline & Focus on end to end service quality management & 229 & 5 \\
\hline & Increase speed & 212 & 25 \\
\hline & Clear commercial incentives and disincentives & 228 & 9 \\
\hline & Improve profitability & 228 & 9 \\
\hline & Resultant based payment model & 174 & 68 \\
\hline & Economies of scale & 202 & 49 \\
\hline & Improved focus on core business & 210 & 32 \\
\hline & Fixed cost to variable cost model & 214 & 23 \\
\hline & Cost optimization & 225 & 11 \\
\hline & Cost predictability & 223 & 13 \\
\hline & Lean organization & 210 & 32 \\
\hline & Collaborative model & 194 & 60 \\
\hline
\end{tabular}


Table $6 \mathrm{~b}$ continued

\begin{tabular}{|c|c|c|c|}
\hline Category & Factor & Score & Rank \\
\hline \multirow{12}{*}{ Organizational } & Risk sharing \& mitigation & 229 & 5 \\
\hline & Alternative method of procurement & 212 & 25 \\
\hline & Delayed and stretched out payment terms & 201 & 50 \\
\hline & Flexibility of operations & 204 & 43 \\
\hline & Management spare time & 212 & 25 \\
\hline & No risk of loss of control & 196 & 57 \\
\hline & Free cash flow & 212 & 25 \\
\hline & No risk of loss of internal expertise & 188 & 65 \\
\hline & Staff to be put to other use & 231 & 4 \\
\hline & Lower entry barriers & 203 & 46 \\
\hline & Retaining of trained staff & 214 & 21 \\
\hline & To reduce network operational costs & 217 & 19 \\
\hline \multirow{32}{*}{$\begin{array}{l}\text { Industry } \\
\text { dynamics }\end{array}$} & Access to key technical experts and global practices & 229 & 5 \\
\hline & Access to global resources & 235 & 3 \\
\hline & Access diverse skills and expertise & 206 & 39 \\
\hline & Leverage unique skills in vendor & 193 & 63 \\
\hline & Access to the latest technology and infrastructure & 218 & 17 \\
\hline & Improve performance of the quality of network & 225 & 11 \\
\hline & Least cost structure & 212 & 25 \\
\hline & Transform business model to compete & 203 & 46 \\
\hline & High quality network build & 210 & 32 \\
\hline & Technological complexities & 210 & 32 \\
\hline & Improve operational efficiency & 207 & 37 \\
\hline & Reliability and availability & 213 & 23 \\
\hline & Focus on the customer & 214 & 21 \\
\hline & Reduce network downtime and service degradation & 198 & 56 \\
\hline & Stiff competition & 206 & 39 \\
\hline & New services faster to market & 189 & 64 \\
\hline & Non-availability of experts within the organization & 159 & 69 \\
\hline & Process, tools and methods & 208 & 36 \\
\hline & Focus on customer acquisition & 216 & 20 \\
\hline & Increasing focus on customer & 199 & 54 \\
\hline & Ease of being updated with new technologies & 206 & 39 \\
\hline & Faster responses to complex network issues & 201 & 50 \\
\hline & Rapid change of technologies & 206 & 39 \\
\hline & Competitive advantage & 212 & 25 \\
\hline & Constant decreasing revenue and margins & 193 & 61 \\
\hline & Constant decline in the Average Revenue Per User (ARPU) & 193 & 61 \\
\hline & Technical shifts & 207 & 37 \\
\hline & Avoid investment on equipment that short end of life & 194 & 59 \\
\hline & Networks sharing to reduce CAPEX and OPEX & 223 & 14 \\
\hline & Under extreme market pressure & 204 & 43 \\
\hline & Make capital funds available for more core areas & 198 & 55 \\
\hline & Incremental revenues for both parties & 181 & 66 \\
\hline \multirow{6}{*}{$\begin{array}{c}\text { Regulatory } \\
\text { Environment }\end{array}$} & Regulatory environment & 218 & 17 \\
\hline & Obsolete technology & 196 & 57 \\
\hline & Passive sharing & 212 & 25 \\
\hline & Networks capacity and coverage sharing & 204 & 43 \\
\hline & To provide Coverage and Capacity & 203 & 46 \\
\hline & No regulation with regard to active sharing & 200 & 53 \\
\hline
\end{tabular}




\section{Factors Influencing the Adoption at Level 5 (Services \& Capacity Management Based)}

Table $6 \mathrm{~b}$ presents the factors influencing the adoption of managed services at Level 5 and their rankings. There are sixty-nine factors identified at this level under three major categories; organizational, industry dynamics and regulatory environment. Of the sixty-nine factors, thirty factors are organizational, thirty-two factors are regarding industry dynamics and seven factors are influenced by the regulatory environment. The top five factors by importance are compliance of service level agreements, accountability and reliability, access to global resources, staff put to other use and access to key technical experts and global practices

\section{DISCUSSION, MANAGEMENT IMPLICATIONS AND CONCLUSION}

Different levels of managed services adopted by the different operators were governed by the number of factors influencing managed services in that level. The number of factors influencing the adoption increases as one progresses through the managed services continuum. This study reveals a number of interesting features.

Most of the factors influencing the adoption of level 1 and level 2 of managed services are the same: Out of the twentytwo factors in level 1 and twenty-four factors in level 2, eighteen factors are common to both levels. Further, most of the factors influencing adoption are related to the organization domain although factors related to industry dynamics are significant in terms of importance; of the common factors, 78 percent are organizational factors and 22 percent are industry dynamic factors. Although there are only four common industry dynamic factors, they rank within the top seven factors by importance. It is noticed that the regulatory environment doesn't influence the adoption of levels 1 $\& 2$ of the managed services spectrum.

Level 1 is a transaction based arrangement related to specific skilled resources provided by a vendor to supplement the local workforce for the basic maintenance of a company's technology assets whereas level 2 is a task based arrangement where the vendor only performs certain tasks or part of the network elements and are responsible for only their activities, for example, field maintenance. In both levels $1 \& 2$ the nature of the services obtained from the vendors are similar but the responsibility and accountability of the vendor varies based on the level of adoption of managed services by the operators. Hence most of the factors are common in these two levels.

These two levels are not influenced by the national regulatory environment factors because the lower end of the spectrum involves basic operations and maintenance of company's technology assets and therefore there is no influence of national regulatory environment factors. Out of the top five factors identified by importance in both levels four factors are common and one factor is unique. In levels $1 \& 2$, the four common factors of the top five factors by importance are access to key competencies on a need basis, access to diverse skills and expertise/expert support, resourcing for "sudden peaks and troughs", specialized areas of work \& access to global resources

Most of the factors identified for level 3, i.e. Project based, are unique compared with levels $1 \& 2$. It was observed that thirty out of thirty-eight identified factors in level 3 are unique compared to levels $1 \& 2$. This indicates that the scope of adopting managed services at level 3 is very different to that for levels $1 \& 2$. The fundamental difference between level 3- project based and levels $1 \& 2$ is that in level 3 all assigned activities need to be completed on time and in an outcome based manner with a start date and an end date whereas in levels $1 \& 2$ the activities are operational and maintenance related and therefore repetitive. However, as in levels $1 \& 2$, most factors influencing the adoption of managed services at level 3 are related to the organization and industry domain. Out of the thirty-eight factors identified at level 3-project based twenty-nine factors are organizational because execution of projects is primarily dependent on the organization objectives and strategy. Furthermore, national regulatory related factors do not have significant influence for the adoption of managed services at level 3 because execution of projects such as network coverage expansion or setting up mobile switch center etc. itself are more dependent on the organization and industry and not regulation dependent except when license conditions are enforced to meet coverage obligations. There is only one factor influenced by the national regulatory environment for this level i.e. meeting coverage obligation.

Most of the factors influencing level 4 (Service Management) are different compared with levels 1, $2 \& 3$. It was observed that forty-one out of sixty-one factors in level 4 are unique compared with levels $1,2 \& 3$. This indicates that the scope for adopting managed services at level 4 is very different to that of levels $1,2 \& 3$. This difference is 
mainly due to the scope of work, ownership and accountability. In level 4 , the services provider takes complete ownership and responsibility for the delivery of both technical and business services according to mutually agreed key performance indicators (KPIs). In contrast, level 1 is a transaction based arrangement related to specific skilled resources provided by a vendor to supplement the local workforce for the basic maintenance of a company's technology assets while level 2 is a task based arrangement where the vendor only performs certain tasks or part of the network elements and is responsible for its activities. Whereas in level 3, the arrangement is project based where the vendor takes responsibility for the network rollout project deliverables and is responsible for the execution of the project end to end.

The majority of the factors influencing the adoption of level 4 are related to organization \& industry dynamics domains. Only three factors are influenced by the regulatory environment. However, the regulatory environment factors have a dominant influence in adopting level 4 of the managed services spectrum for creating the required regulatory environment to adopt managed services in terms of policy frame work to deal with cyber security, data protection, hosting subscriber data outside the country, active and passive infrastructure sharing, obsolete technology etc.

Most of the factors influencing the adoption at level 4 (Service management) and level 5 (Service \& Capacity management) of managed services are the same. Out of the sixty-one factors in level 4 and sixty-nine factors in level 5, fifty-one factors are common to both levels. Additionally, it is observed that the factors influencing the adoption at level 4 is almost a subset of the factors influencing the adoption at level 5. Further, the factors related to the national regulatory environment have a dominant influence in adopting level 5 of the managed services spectrum. There are very few factors common to level 5 and levels $1,2 \& 3$.

The commonality between levels 4 and 5 is because the services provider takes complete ownership and responsibility for the delivery of both technical and business services according to mutually agreed key performance indicators (KPIs) for service management. In addition to the service management, the service provider at level 5 assumes complete end-to-end responsibility for the communications infrastructure design, implementation, deployment, management and provides required capacity as and when required.

In Level 5, out of the sixty-eight factors, thirty-two factors are related to industry dynamics. The key reasons for this are service delivery, service levels, capacity building, focus shift on value chain, active and passive infrastructure sharing, constant decline of tariffs, stiff competition etc. Similar to level 4-service management based, the regulatory environment factors have dominant influence in adopting level 5 of service and capacity management based for creating the required regulatory environment to adopt managed services in terms of policy frame work to deal with cyber security and data protection, necessary policies related to hosting subscriber data outside the country, active and passive infrastructure sharing, policy for obsolete technology etc.

\section{Management Implications and Conclusion}

This study investigated the factors influencing the adoption of managed services at different levels, rather than as a whole, in general. Thus, it is a new way of looking at the problem, as the mobile operator can adopt managed services at any level. Thirty-four new factors have been identified from the case studies for different levels of managed services in addition to the existing knowledge base about factors influencing the adoption of managed services.

The results of this research show that there is a clear pattern emerging between levels when moving through the consecutive levels of managed services from transaction based to services \& capacity management based. Five levels of managed services can be divided into three distinct groups, levels $1 \& 2$, level 3 and levels $4 \& 5$. Level 1Transaction based is almost a subset of level 2 -Task based, and level 4-Service management is a sub set of level 5 services \& capacity management. Level 3 stands unique compared with the other levels.

Organizational and industry dynamics drivers influence all levels of mobile telecom managed services. However, the national regulatory environment factors are very important in adopting managed services at level 4 -services management \& at level 5- services \& capacity management. 
The comprehensive list of factors identified and prioritized at each level of managed services is helpful to the mobile phone operators in considering the adoption of managed services. The operator intending to adopt managed services could identify the drivers that influence managed services at different levels within the three major groups as tabulated in tables 4,5 and 6 which can then be used to decide which level of managed services the company should adopt. The national regulatory environment related factors identified for levels $4 \& 5$ of the managed service will help national policy makers prepare the ground for operators to adopt managed services at levels $4 \& 5$.

\section{AUTHOR BIOGRAPHIES}

Hassan Ismail (Contact author) is a DBA candidate at the School of Management, Asian Institute of Technology, Thailand. He is a Chartered Engineer, obtained his Bachelor of Engineering at the University of Peradeniya and MBA from the University of Colombo Sri Lanka. He is presently holding the position of General Manager in one of the mobile operators in Sri Lanka. Hassan Ismail is a regular speaker in the outsourcing and managed services world congress in countries like Singapore, Dubai, Turkey, Germany, England etc. He was a key stakeholder in setting up two greenfield telecom operators in Sri Lanka. Hassan Ismail posses in depth knowledge in the area of outsourcing and managed service specially in the information technology and telecommunication industry. Email: mia.hassan16@gmail.com

Nazrul Islam is a Professor at the School of Management, Asian Institute of Technology (AIT), Bangkok, Thailand. $\mathrm{He}$ is credited with large number of publications in the form of books, book chapters, articles in international refereed journals, conference proceedings and technical reports in the areas of innovation \& knowledge management, technology transfer, application of IT in hotel industry, and energy technology. He served as a consultant to the government agencies, research institutions, industries, and UN agencies. Prof. Islam is an Area Editor of the journal The International Technology Management Review. Email: nazrul@ait.asia, nazrul48@gmail.com

\section{REFERENCES}

Adeleye, B. C., Annansingh, F., \& Nunes, M. B. (2004). Risk management practices in IS outsourcing: an investigation into commercial banks in Nigeria. International Journal of Information Management, 24(2), 167-180.

Ambriola, A. (2012). Delivering new services faster with a MS partner. Proceedings of Managed Services, World congress in Berlin, Germany.

Ang, S., \& Straub, D. W. (1998). Production and transaction economies and IS outsourcing: a study of the US banking industry. MIS Quarterly, 535-552

Baldwin, L. P., Irani, Z., \& Love, P. E. (2001). Outsourcing information systems: drawing lessons from a banking case study. European Journal of Information Systems, 10(1), 15-24.

Barney J. (1991). Firm Resources and Sustained Competitive Advantage. Journal of Management, 17(1), 99. Retrieved from http://www.isu.uzh.ch/som/stu/Teaching/FS10/MA/som/Barney_1991_strategy.pdf

Blumberg, D. (1998). Strategic assessment of outsourcing and downsizing in the service market. Managing Service Quality: An International Journal, 8(1): 5-18.

Calvin A. (May, 2010). Telecom Managed Services Will Transform Carrier Business Models: Report. Retreived from: http://mspalliance.tmcnet.com/topics/managed-serviceproviders/articles/85188-telecom-managed-services-willtransform-carrier-businessmodels.htm

Casale, F. (2001), IT index 2001.The Outsourcing Institute/ Sunguard Sourcing Report.

Chin, C. (May, 2003). My bit-outsourcing-driving business value. The Edge Malaysia.

Clark Jr, T. D., Zmud, R. W., \& McCray, G. E. (1995). The outsourcing of information services: transforming the nature of business in the information industry. Journal of Information Technology, 10(4), 221-237.

Claver, E., González, R., Gascó, J., \& Llopis, J. (2002). Information systems outsourcing: reasons, reservations and success factors. Logistics Information Management, 15(4), 294-308.

Clott, C. (2004). Perspectives on global outsourcing and the changing nature of work, Business and Society Review, 109(2):153170.

Corbett, M. (1998). Outsourcing: beyond buying services. Facilities Design \& Management, 17(1), 40-43.

Corbett, M. (2005). Leveraging managed services to advance your business. An executive briefing on improving business performance through a managed services approach to meeting an organization's communications needs.

Cross, J. (1995). IT outsourcing: British Petroleum's competitive approach. Long Range Planning, 28(4), 128-128.

DiRomualdo, A. \& Gurbaxani, V. (1998). Strategic Intent for IT Outsourcing. University of California. Retrieved from: http://repositories.cdlib.org/crito/business/145.

Domberger, S. (1998). The Contracting organization: A Strategic Guide to Outsourcing. Oxford [England]: University Press. 
Dominguez, L. (2006). The Manager's Step-By-Step Guide to Outsourcing. New York: McGraw-Hill.

Embleton, P. \& Wright, P. (1998). A practical guide to successful outsourcing. Empowerment in Organizations, 6(3): 94-106.

Ericsson. 2007. Managed services' impact on the telecom industry. White Paper.

Fischer G. (2012). Bring value to Operators' business. Proceedings of Managed services World congress in Berlin, Germany.

Fischer, J., Hirschheim, R. \& Jacobs, R. (2008). Understanding the outsourcing learning curve: a longitudinal analysis of a large Australian company. Information Systems Frontiers, 10, 165- 178.

GSMA (October, 2016). Global cellular market trends and insight. Third Quarter. Retrieved from https://www.gsmaintelligence.com/research/?file=262483452a447a1b68bc88162bc919cd\&download

Gonzalez, R., Gasco, J., \& Llopis, J. (2005). Information systems outsourcing risks: a study of large firms. Industrial Management \& Data Systems, 105(1), 45-62.

Hu, Q., Saunders, C., \& Gebelt, M. (1997). Diffusion of information systems outsourcing: A reevaluation of influence sources. Information Systems Research, 8(3), 288-301.

Huber, R. L. (1993). How Continental Bank outsourced its crown jewels. Harvard Business Review, 71(1), 121-129.

Ismail, H. (2012). Reinforcing the do's and don't's of MS engagements- from the operator and vendor perspective. Proceedings of Managed Services World congress in Berlin, Germany.

ITU. (2017). ITU: Committed to connecting the world. Retreived Feb 2016. Retreived from

http://www.itu.int/en/Pages/default.aspx

Jakobson, P. (2012). New Business Models wholesale network sharing. Proceedings of Managed Services World congress in Berlin, Germany.

Janko, W. H., \& Koch, S. (2005). Sourcing decisions in the finance sector: economies of scale and knowledge management. International Finance Symposium, Istanbul, 1-14.

Jennings, D. (2002). Strategic sourcing: benefits, problems and the contextual model, Management Decision, 40(1): 26-34.

Jiang, B. \& Qureshi, A. (2006). Research on outsourcing results: current literature and future opportunities, Management Decision, 44(1): 44-55.

Khan, J. (2012). MS Relationship Management. Proceedings of Managed Services World congress in Berlin, Germany.

Knight-John, M. (2008). Telecom Regulatory and policy environment in Sri Lanka: Results and analysis of 2008 TRE Survey. Institute of Policy Studies Sri Lanka.

Knight-John, M. (2011). Privatization, competition and regulatory governance: A case study of sri lanka's telecom sector. Unpublished Ph.D. thesis. The University of Manchester Faculty of Humanities.

Koch, S. (2008). Sourcing decisions in the finance sector: current state and focus on economies of scale and knowledge management. International Journal of Services, Economics and Management, 1(2), 163-182.

Kuisch, E. (2012). Our need for managed services. Proceedings of Managed Services World congress in Berlin, Germany.

Lacity, M. \& Hirschheim, R. (1993). The information systems outsourcing bandwagon. Sloan Management Review, 35(1), 73-86.

Lacity, M. C., \& Willcocks, L. P. (1998). An empirical investigation of information technology sourcing practices: Lessons from experience. MIS Quarterly, 22(3).

Lacity, M. \& Wilcox, L. (2004). Global Information Technology Outsourcing: In Search of Business Advantage: John Wiley \& Sons.

Lancellotti, R., Scheim, O., Spang, S. \& Stadler, V. (2003). CT and Operations outsourcing in banking. Wirtschaftsin-Formatik, $45(2), 131-141$.

Langlais T. (2012). Ensuring consistent customer experience service quality with a managed service approach. Proceedings of Managed Services World congress in Berlin, Germany.

Loh, L. \& Venkatraman, N. (1992). Determinants of information technology outsourcing: a cross sectional analysis. Journal of Management Information Systems, 9(1),7-24.

Lonsdale, C., \& Cox, A. (2000). The historical development of outsourcing: the latest fad? Industrial Management \& Data Systems, 100(9), 444-450.

Lurin, P. \& Legrand, L. (2014) Re-visiting the financial benefits of Managed Services and Infrastructure Sharing for Telcos. White Paper.

Lynch, C. (2004). Why outsource? Supply Chain Management Review, 8(7), 44-49.

Manish, S. \& Rohini, W. (2007). Outsourcing Models: Aligning Sourcing Strategy to Business Objectives. White Paper, 2-12.

McLellan, K., Marcolin, B., \& Beamish, P. (1995). Financial and strategic motivations behind IS outsourcing, Journal of Information Technology, 10(4), 299-321.

Mead, B. (2012). End user experience in a managed services context. Proceedings of Managed Services World congress in Berlin, Germany.

Möller, K. K., \& Halinen, A. (1999). Business relationships and networks: Managerial challenge of network era. Industrial Marketing Management, 28(5), 413-427.

Nam, K., Rajagopalan, S., Rao, H. \& Chaurdaury, A. (1996). A two-level investigation of information systems outsourcing, Communications of the ACM, 39(7), 36-44.

Odindo, C., Diacon, S., \& Ennew, C. (2004). Outsourcing in the UK financial services industry: the Asian offshore market. In Report to the Financial Services Research Forum: Nottingham.

Prahalad, C. \& Hamel, G. (1990). The core competence of the corporation. Harvard Business Review, 68(3), 79-91. 
Quinn, J. (1999). Strategic outsourcing: leveraging knowledge capabilities. Sloan Management Review, 40(4),9-21.

Quinn, J. (2000). Outsourcing innovation: the new engine of growth, Sloan Management Review, 41(4), 13-28.

Quinn, J. \& Hilmer, F. (1994). Strategic outsourcing, Sloan Management Review, 35(4), 43-55.

Razzaque, M. \& Sheng, C. (1998). Outsourcing of logistics functions: a literature survey. International Journal of Physical Distributions and Logistics Management, 28(2), 89-107.

Richardson, H.L. (1990). Explore outsourcing. Transportation \& Distribution 31(7), 17-20

Samarajeewa, R. \& Dokeniya, A. (2004). Regulation and investment: Sri Lanka case study, including a pilot assessment of the telecom regulatory environment. World Dialogue on Regulation for Network Economies.

Schmitz, M. (2012). Green Outsourcing: How to achieve the best of two worlds. Proceedings of Managed Services World congress in Berlin, Germany.

Seddon, P., Cullen, S. \& Leslie P. Willcocks. (2002). Does Domberger's Theory of the contracting organizations explain satisfaction with IT outsourcing? 23 $3^{\text {rd }}$ International Conference on Information Systems.

Szaniawski, K. (2012). Key trends and influences in Managed services. Proceedings of Managed Services World congress in Berlin, Germany.

Thomas, F. (2010). Benchmark-Based Assessment of Out-tasking, Outsourcing, and Managed Services for Mobile Network Operators. 2010 IEEE/IFIP Network O\&M Symposium. Retrieved from: http://ieeexplore.ieee.org

Trunick, P. (1989). Outsourcing: a single source for many talents. Transportation and Distribution, 30(7), 20-3.

Weerakkody, V., Currie, W. L., \& Ekanayake, Y. (2003). Re-engineering business processes through application service providers: Challenges, issues and complexities. Business Process Management Journal, 9(6), 776-794.

Whalley, J. \& Curwen, P. (2005). Consolidation vs fragmentation: The case of the European mobile communications market. European Business Review, 17(1), 21-35

Zhao, Y., \& Zhu, Q. (2012). Exploring the motivation of participants in crowdsourcing contest. International Conference on Information Systems (ICIS). December 2012. Association for Information Systems. 


\section{ANNEXURE 1}

\section{Factors Effecting Managed Services in the Telecom Industry}

\begin{tabular}{|c|c|}
\hline $\begin{array}{l}\text { Factors effecting managed services } \\
\text { in the telecom industry }\end{array}$ & Sources \\
\hline \multicolumn{2}{|l|}{ 1. Organizational } \\
\hline Accountability and reliability & Ambriola (2012) \\
\hline Avoid crowdsourcing & Zhao and Zhu (2012) \\
\hline Specific commercial incentives and disincentives & Ismail (2012) \\
\hline Compatibility of Service Level Agreements (SLAs) & Ismail (2012) \\
\hline Compliance of service level Agreements (SLAs) & Ismail (2012) \\
\hline Cost leadership & Ericsson $(2007)$ \\
\hline Cost optimization & $\begin{array}{l}\text { Loh and Venkatraman (1992); McLellan et al. (1995); Ang and Straub } \\
\text { (1998); Casale (2001); Baldwin et al. (2001); Odindo et al. (2004); } \\
\text { Fischer et al. (2008) }\end{array}$ \\
\hline Cost predictability & Schmitz (2012) \\
\hline Cost reduction & $\begin{array}{l}\text { Trunick (1989); Richardson (1990); Gonzalez et al. 2005; Mead } \\
\text { (2012); Schmitz (2012) }\end{array}$ \\
\hline Cost savings & Embleton and Wright (1998); Claver et al. (2002) \\
\hline Economies of scale & Schmitz (2012) \\
\hline End to end vendor accountability for projects & Mead (2012) \\
\hline Fixed to variable cost model & Huber (1993); Baldwin et al. (2001) \\
\hline Flexibility of operations & Khan $(2012)$ \\
\hline Focus on core competencies & $\begin{array}{l}\text { Prahalad and Hamel (1990); Quinn and Hilmer (1994); Weerakkody } \\
\text { et al. (2003) }\end{array}$ \\
\hline Focus on end to end service quality management & Ambriola (2012) \\
\hline Focus on Key Performance Indicators (KPIs) & Ambriola (2012) \\
\hline Free cash flow & Embleton and Wright (1998) and Claver et al. (2002) \\
\hline Improved profitability & Quinn (1999) \\
\hline Improved focus on core business & Quinn (1999); Baldwin et al. (2001); Odindo et al. (2004) \\
\hline Increased ability to adopt new technologies & Mead (2012) \\
\hline Increased speed & McLellan et al. (1995); Quinn (2000) \\
\hline Increased flexibility & Khan (2012) \\
\hline Lean organization & Nam et al. (1996); Ang and Straub (1998) \\
\hline No risk of loss of control & Blumberg (1998); Lonsdale and Cox (2000) \\
\hline Non- availability of experts within the organization & Jiang and Qureshi (2006) \\
\hline Operational ease & $\begin{array}{l}\text { McLellan et al. (1995); Clark et al. (1995); Hu et al. (1997); Baldwin } \\
\text { et al. (2001) and Chin (2003) }\end{array}$ \\
\hline Resourcing for "sudden peaks and troughs" & Jiang and Qureshi (2006) \\
\hline Risk sharing \& mitigation & $\begin{array}{l}\text { McLellan et al. (1995); Clark et al. (1995); Hu et al. (1997); Baldwin } \\
\text { et al. (2001); Chin (2003) }\end{array}$ \\
\hline Scalability & $\begin{array}{l}\text { McLellan et al. (1995); Clark et al. (1995); Hu et al. (1997); Baldwin } \\
\text { et al. (2001); Chin (2003) }\end{array}$ \\
\hline Spare management time & Ericsson (2007); Corbett (2005) \\
\hline Speedy network rollout & Mead (2012) \\
\hline Staff put to other use & Quinn and Hilmer (1994); Weerakkody et al. (2003) \\
\hline Staff reduction & Khan (2012) \\
\hline Improvement of the competency level & Szaniawski (2012) \\
\hline Reduction of network operational costs & Mead (2012); Khan (2012) \\
\hline Training and retraining & Szaniawski (2012) \\
\hline \multicolumn{2}{|l|}{ 2. National Regulatory Environment } \\
\hline Regulatory environment & $\begin{array}{l}\text { Odindo et al. (2004); Knight-John (2008); Knight-John (2011); } \\
\text { Samarajiva \& Dokeniya (2004) }\end{array}$ \\
\hline Active \& passive infra sharing policies & Lurin \& Legrand (2014); Jakobson (2012) \\
\hline
\end{tabular}




\section{Industry Dynamics}

Access diverse skills and expertise

Access to best in class organization and process

Access to global resources

Access to key competencies on need basis

Access to key technical experts and global practices

Access to the latest technology and infrastructure

Competitive advantage

Constant decreasing revenue and margins

Ease of being updated with new technologies

Expertise or capability of vendor

Faster responses to complex network issues

Focus on customer acquisition

Focus on the customer

Improvement of operational efficiency

Improvement of performance of the quality of network

Increased complexities

Increased focus on customers

Incremental revenues for both parties

Least cost structure

Capital funds available for more core areas

Need for special skills and training

New service fast (New service faster to market)

Process, Tools and methods

Rapid change of technologies

Reduce network downtime and service degradation

Specialized vendors

Technical shifts

Technological complexities

Handling increased complexity

Extreme market pressure
McLellan et al. (1995); Cross (1995); Clark et al. (1995); Lacity and Willcocks (1998); Baldwin et al. (2001); Casale (2001); Odindo et al. (2004); Adeleye et al. (2004)

Schmitz (2012); McLellan et al. (1995); Cross (1995); Clark et al. (1995); Lacity and Willcocks (1998); Baldwin et al. (2001); Casale (2001); Odindo et al. (2004); Adeleye et al. (2004) Clott (2004)

Schmitz (2012); McLellan et al. (1995); Cross (1995); Clark et al. (1995), Lacity and Willcocks (1998); Baldwin et al. (2001); Casale (2001); Odindo et al. (2004); Adeleye et al. (2004)

McLellan et al. (1995); Cross (1995); Clark et al. (1995); Lacity and Willcocks (1998); Baldwin et al. (2001); Casale (2001), Odindo et al. (2004); Adeleye et al. (2004)

McLellan et al. (1995); Cross (1995); Casale (2001); Lacity and Willcocks (1998); Odindo et al. (2004); Adeleye et al. (2004) Clott (2004)

Ericsson (2007) Jakobson (2012)

McLellan et al. (1995); Cross (1995); Casale (2001); Lacity and Willcocks (1998); Odindo et al. (2004); Adeleye et al. (2004) Jennings (2002)

McLellan et al. (1995); Quinn (2000)

Clark et al. (1995); DiRomualdo and Gurbaxani (1998); Odindo et al. (2004)

Clark et al. (1995); DiRomualdo and Gurbaxani (1998); Odindo et al. (2004)

Loh and Venkatraman (1992), McLellan et al. (1995); Clark et al

(1995); Baldwin et al. (2001); Lancellotti et al. (2003)

Langlais (2012)

Baldwin el al. (2001)

Quinn and Hilmer (1994); Weerakkody et al. (2003); Fischer (2012)

Schmitz (2012)

Ericsson (2007); Trunick (1989); Richardson (1990); Gonzalez et al. (2005)

Corbett (1998); Razzaque and Sheng (1998); Trunick (1989); Lynch (2004)

Szaniawski (2012)

Ericsson (2007); Corbett (2005)

DiRomualdo and Gurbaxani (1998); Quinn (2000); Baldwin et al.

(2001); Odindo et al. (2004)

Kuisch (2012)

Jakobson (2012)

Quinn (2000); Janko and Koch (2005); Koch (2008)

Ericsson (2007); McLellan et al. (1995); Cross (1995); Casale (2001);

Lacity and Willcocks (1998); Odindo et al. (2004); Adeleye et al. (2004)

McLellan et al. (1995); Cross (1995); Casale (2001); Lacity and Willcocks (1998); Odindo et al. (2004); Adeleye et al. (2004)

Baldwin el al. (2001)

Calvin (2010) 


\section{NOTES}

